\title{
Protein-losing enteropathy demonstrated on Tc-99m HSA
}

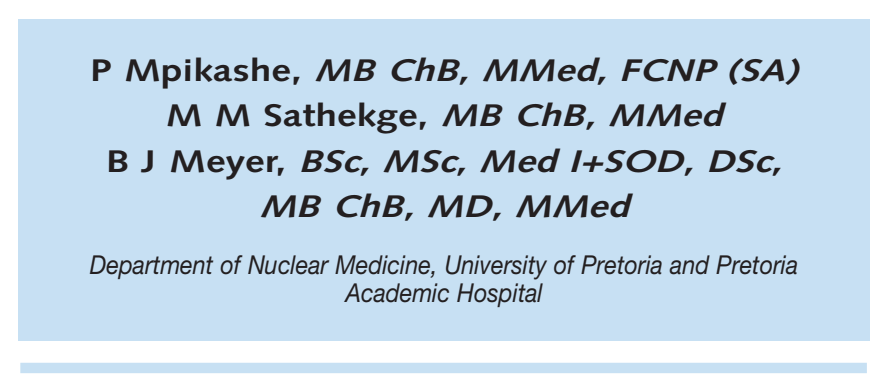

\section{Introduction}

Protein-losing enteropathy (PLE) is defined as a condition in which excess protein loss into the gastrointestinal lumen is severe enough and chronic diarrhoea. Laboratory tests at the time of scintigraphy showed hypoproteinaemia $(53 \mathrm{~g} / \mathrm{l})$ and hypoalbuminaemia $(20 \mathrm{~g} / \mathrm{l})$. The findings of renal and liver function tests were normal. On physical examination, vital signs were normal and the patient was saturating at $97 \%$. The chest was clear bilaterally with normal heart sounds. The abdomen was soft with no tenderness.

Clinically, the lesions were brownish macules visible on the lower lips and buccal mucosa, and dorsa of the hands, forearms and lower limbs. Stool cultures were negative for pathogens. Colonoscopy revealed hundreds of polyps.

Peutz-Jeghers syndrome and PLE were considered as part of the differential diagnosis, and further investigation was needed. For the

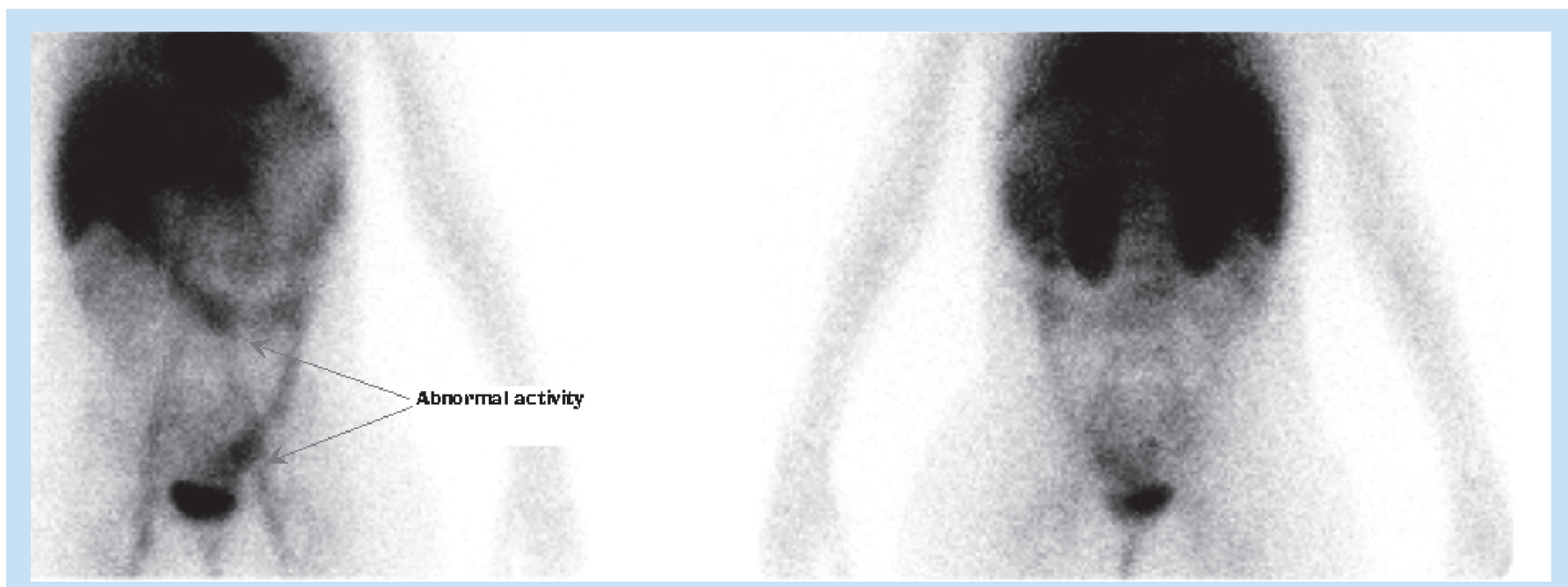

Fig. 1. Tc-99m HSA, 6-hour anterior and posterior images demonstrating abnormal tracer accumulation (arrows) in keeping with evidence of PLE.

to produce hypoproteinaemia. ${ }^{1}$ Previously reported procedures for the detection of protein loss have many limitations (such as rapid reabsorption of the radiolabel, unstable protein binding both in vivo and in vitro, and limited availability ${ }^{2}$ ) and were, moreover, cumbersome as well as unpleasant, as they involved 24-hour urine and stool collection. The study was also prone to error owing to the long urine and stool collection period.

Although Tc-99m-labelled human serum albumin (HSA) has been used to diagnose PLE with success, a literature search yielded few results, thus raising the question of the diagnostic value of this radiotracer. ${ }^{2,3}$

The benefits of using a Tc-99m-labelled tracer are manifest and include:

- shorter duration for performing the study

- good imaging characteristics

- no stool or urine collection

\section{Case report}

An 11-year-old girl presented with a 6-month history of weight loss, fatigue, loss of appetite, hyperpigmented macules, general body swelling

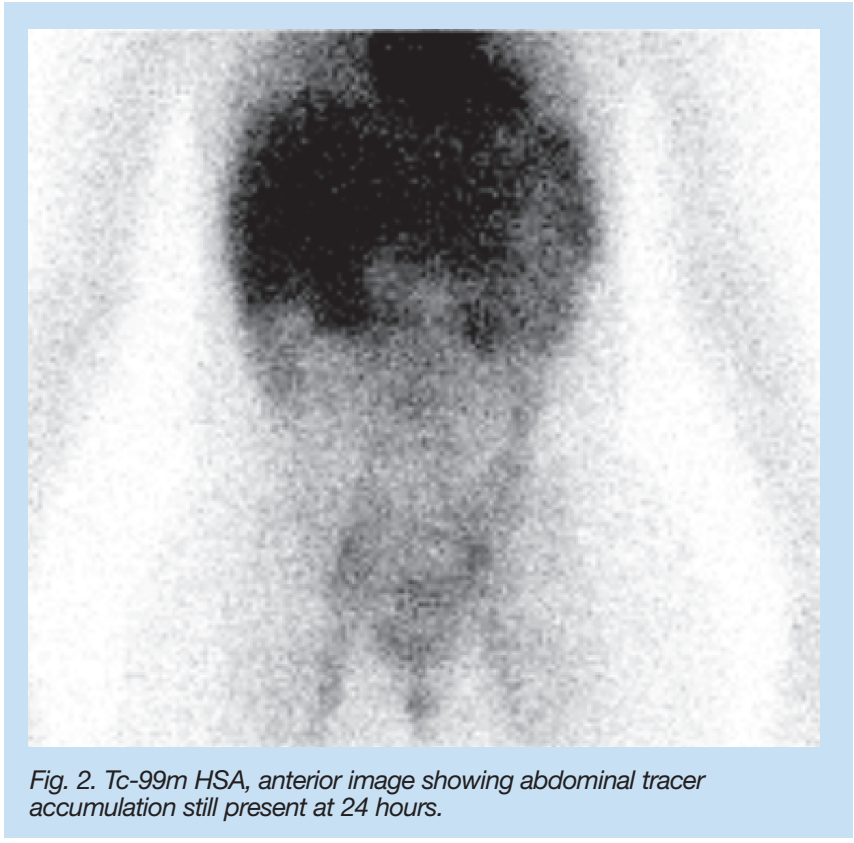


confirmation of PLE, Tc-99m-labelled human serum albumin (HSA) scintigraphy was performed. Tc-99m HSA $444 \mathrm{MBq}$ was injected intravenously, and scintigraphic images were obtained 10 minutes, 30 minutes, 40 minutes, 1 hour, 2 hours and 6 hours after injection; 24-hour imaging was also performed. Images of the thyroid were also obtained after 30 minutes to monitor for free pertechnetate.

Abnormal tracer accumulation was visualised in the bowel from the 6-hour image up to the 24-hour image (Figs 1 and 2). No tracer activity was noted in the thyroid, stomach and salivary glands.

\section{Discussion}

PLE is characterised by excessive loss of serum proteins in the gastrointestinal tract. It may be caused by a diverse group of disorders such as gastric carcinoma, ulcerative colitis, regional enteritis, Whipple's disease, tropical and non-tropical sprue, and giant hypertrophy of the gastric mucosa. ${ }^{4}$ Peutz-Jeghers syndrome is also associated with proteinlosing gastroenteropathy. ${ }^{5}$ In our case, the patient had Peutz-Jeghers syndrome; this is a dominantly inherited human disorder characterised by gastrointestinal hamartomatous polyposis and mucocutaneous melanin pigmentation. ${ }^{6}$

Localising the site of protein loss and its quantification are important in the management of PLE. Faecal clearance of alpha ${ }_{1}$ antitrypsin is an inexpensive and quite reliable test of PLE, and is measured by determining stool volume and both stool and plasma alpha-antitrypsin concentrations. However, it is unable to ascertain the site of the leak; to do so, iodine 131 polyvinylpyrrolidine, iodine 125 polyvinylpyrrolidone, chromium 51-labelled albumin, chromium 51 chromic chloride, iodine 125 albumin, indium 111 chloride, indiumtransferring Tc-99m diethylenetriaminepenta-acetic acid HSA, Tc-99m dextran, and Tc-99m human immunoglobulin have been used with success. ${ }^{2}$ Technetium-labelled HSA is valuable for the diagnosis of PLE.
A lower radiation burden, faster background clearance and higher in vitro and in vivo stability support Tc-99m HSA as a more effective agent for PLE imaging.

Although Tc-99m is the ideal tracer for the imaging of PLE, it does not allow quantification of protein loss due to its short physical half-life. On the other hand, Tc-99m-labelled agents cannot cross intestinal mucosa because of the impermeable barrier between the vascular endothelium and luminal contents. They therefore remain in the vascular compartment with a long intravascular half-life, ${ }^{2,7}$ which is helpful in localising the site of enteric protein loss. Hence, sites of protein loss may also be demonstrated within the 24-hour imaging period.

Since technetium is taken up and trapped by the thyroid gland, it is essential to image the thyroid gland at 30 minutes to confirm that the binding of albumin to the technetium is good. Other organs that normally demonstrate technetium accumulation include the stomach and salivary glands, which further confirms the need to ensure excellent binding. Detecting the location of a leak is very useful for diagnosis and therapy planning, especially if surgery is needed.

Based on the abovementioned advantages of using technetiumlabelled tracers, we recommend the continuing use of technetiumlabelled HSA in the diagnosis of PLE.

1. Greenberger NJ, Isselbacher KJ. Disorders of Absorption. New York: McGraw-Hill, 1998; 1616-1633.

2. Nan-Tsing C, Bi- Fang L, Shang-Jyh H, Jer-Ming C, Gin-Chung L, Hsin-Su Y. Protein-losing enteropathy: diagnosis with Tc-99m labelled human serum albumin scintigraphy Radiology 2001; 219: 86-90.

3. Seok JW, Kim SJ, Lee SH, Kim YK. Protein-losing enteropathy detected on Tc-99m HSA and Tc-99m MDP scintigraphy. Clin Nucl Med 2002; 27: 431-433.

4. Nikolaos N, Konstantinos T, Olga G, Dimitros G. Protein-losing enteropathy as the principal manifestation of constricitive pericarditis. J Gen Intern Med 2005; 20: C5-C7.

5. Kazuhiro Y, Masafumi I, Yosuke A, et al. Peutz-Jeghers polyposis with bleeding from polyps of the sigmoid colon successfully treated by laparoscopic surgery. Dig Endoscopy 2003; 15: 51-54

6. Gennaro S, Concetta FC, Filippo C, Gianluca T, Salavatore C. A case of protein-losing enteropathy caused by intestinal lymphangiectasia in a preterm infant. Pediatrics 2001; 107: 416-417

7. Halaby H, Bakheet SM, Shabib S, et al. Tc-99m human serum albumin scans in children with protein losing eneteropathy. J Nucl Med 2000; 41:215. 